articulate directly with the centrocorsal basin, while their inferolateral angles are truncated so as to make room for the intervening basals.

The basals of Phanogen'a appear to be in a condition intermediate between that of Anterlon and Actinometra. Lovén describes them as internal and concealed, forming a small rosette with a central pentagonal opening, and marked on its ventral face by five sinuses, which receive processes from the sutures of the first radials.

We have thus a very interesting series of transitions from Antedon to Pentacrinus; firstly through Phanngenia and Actinometra to Comaster; thence to Solanocrinus costatus, in which the basals resemble those of Comaster, but the centrodorsal basin is elongated and visibly composite ; and finally to $S$. jageri, Goldfuss, in which the basals are so wide that they are completely in contact with one another all round, precisely as in Pentacrinus; this genus then only differs as far as the stem and basals are concerned, from S. jegeri, by the fact that its nodal cirrhus-bearing stem-segments are not fused together, but separated from one another by more or fewer of the internodal ones which do not bear cirrhi.

Solanocrinus thus constitutes, as already pointed out by Gold. fuss, a very interesting intermediate form between the stalked Pentacrini and the ordinary free-living Comatule, which are only stalked in their young stages.

Besides the above-mentioned four generic types, or rather five, if Pictet be right in erecting $S$. jageri into a separate genus, Lamarck's name Comatula also includes the beautiful little fivearmed Ophiocrimus from the Philippines; unfortunately we do not yet know either the condition of its basals or the anatomy of its soft parts, and can therefore form no opinion as to its relations to the other members of the family.

As these five or six types are all equally entitled to the name Comatula, it becomes necessary in any systematic work on the family to give them distinct generic or sub-generic names, especially as in one or two cases the same specific name has been given to two or more types. Thus the Comatula multiradiata, Goldfuss, is a Comaster, while the C.multiradiata of Lamarck is an Actinometra; and again the C. armata of Pourtales is an Anttdon, while C. armata, Semper, is an Actinometra.

For ordinary dredging work, however, on the British coasts, where Antedon is the only representative of the family, it is not so necessary to discard a common and better known name in favour of one which, although scientifically correct, and considerably older, has only recently come into general use, especially when, as Mr. Stebbing remarks, its meaning and pronunciation are alike difficult to determine; and though the designation Comatula rosacca may, scientifically regarded, be a somewhat loose one, it is now so well known that the use of it is not likely to lead to any serious mistakes in synonymy among working naturalists.

Würzburg, Bavaria

WiTH reference to the names Antedon and Comatula, will you allow me to say that the former has been applied to a genus of lamellicorn beetles since the year $18_{32}$ ? Comatula has been in use from nearly the beginning of the present century, and it is not only found in the works of Fleming, Forbes, Sars, Owen, G. H. Lewes ("Seaside Studies"), Carus, and others, but it must be a familiar word to many who have seen the splendid tank of those crinoids in the Naples aquarium. And now that we are bidden to change it "on the grounds of priority," may we inquire if the "grounds" of long custom (in this case more than sixty years) are to be invariably set aside? Dr. J. E. Gray, who had a sort of mania for change, tried in 1848 to restore de Freminville's name of Antedon. He went a step further, and, after Pennant, adopted Linck's specific name (so far as Linck had any idea of specific names, for they were unknown in his day) of "decameros," so that the advocates of alsolute priority uill have to take "Antedon decameros" as the designation of Comatula rosacea.

In Gemminger and von Harold's "Catalogus Coleopterorum," Antedon is derived from $\dot{\alpha} \nu \tau l$ and $\dot{o} \delta \dot{\omega} \nu$, and consequently spelt Antodon; I do not see its application in either case.

I should be glad to see the "xules of zoological nomencla. ture" (Mr. Hughes means, I presume, those of the British Association) better observed if it led to the exclusion of such barbarisms as Butzkopf, Gatyghol, Sing-sing, Nabiroup, and others, which many of the readers of NATURE will probably be astonished to find in our modern scientific nomenclature. May we inquire if such a description as that of the celebrated " Hister australis," viz., "nigro-cyaneus, nitidus, subtus ater," which would apply to hundreds of species of Histeridæe, is entitied to claim the protection of the law of priority? I think we may sometimes fall back with advantage on the law of common sense, or that, at any rate, it may be allowed to supplemen: the law of priority.

December 23, 1876 FRANCIS P. PASCOE

\section{Sea Fisheries}

My chief reason for again intruding on you is for the purpose of supplying some omissions in Prof. Newton's quotations from Prof. Baird's first Report. In this Prof. Baird speaks of the destructive agency of the blue-fish. He states that about a million and a quarter of these fishes are caught annually on the New England coast, but that any one who has watched the blue-fish there must feel convinced that not one in a hundred of these fishes is caught; he allows twenty fish of other kinds as being devoured or mangled by each blue-fish daily, and then goes into a calculation of the thousands of millions of fish which must be destroyed by the blue-fish. I am writing this from memory, but I believe I am correct. Prof. Baird then says (I give this verbatim), p. 23:-_" Indeed I am quite inclined to assign to the blue-fish the very first position among the injurious influences that have affected the supply of fish on the coast. Yet, with all this destruction by the blue-fish, it is probable that there would not have been so great a decrease of fish as at present but for the concurrent action of man."

This, the other cause of decrease, on which Prof. Baird lays great stress, is the numerous traps and pounds along the coast ; but in Clause XII. of the same summary from which Prof. Newton quoted, I find the following :-

"As there is reason to believe that scup, and to a less degree other shore-fisb, as well as blue-fish, have several times disappeared at intervals to a greater or less extent, within the historic period of New Lngland, we cannot be certain that the use of traps and pounds within the last ten years has actually produced the scarcity complained of. The fact, however, that these engines do destroy the spawning fish in so great numbers renders it very probable that they exercise a decided influence."

Prof. Newton does not speak with his usual scientific precision when he refers only to the cod, and doubtfully to the mackerel, having decreased owing to the scarcity of the alewives-m" cod, haddock, aud hake" being mentioned in the same paragraph. Nor does it seen to me quite worthy of my friend, in discussing the probabilities of overfishing in the sea, to try to prove lis case by bringing forward an instance of overfishing in the rivers leading to a smaller supply of food at a certain season for purely sea fish on the coast, and therefore a decrease in those sea fish.

Dogfish are "predatory and mischievous:" they plunder the nets, and they tear the nets in pieces.

Athenreum Club, December 29 E. W. H. Holdswokti

[Pressure upon our space has necessitated a curtailment of this letter. This correspondence must now cease.-En.]

\section{The "Sidereal Messenger"}

IN NATURE (vol. xv. p. 49), in a notice of Mr. Knobel's "Catalogue of the Literature of Sidereal Astronomy," attention is called to the rarity of the Sidereal Messenger. We have, in the library of this Observatory, only one copy of that periodical. I hope, however, soon to be in possession of a few copies of vol. $i$. If so I shall take pleasure in sending one of them to the Royal Astronomical Society. All of Prof. Mitchel's measures of double stars (about 300) are now in the hands of the printer and will be published before the close of the year.

Cin. Obs., September 12

\section{South Polar Depression of the Barometer}

Mr. Clement Lev, writing in Nature (vol. xv. p. 157), thinks that the great depression of the barometer throughout the region round the South Pole as compared with that round the North Pole, is "mainly due to superior evaporation in the water hemisphere generally." This seems an inadequate cause, for evaporation must be small in the very low temperatures which appear to be constant at all seasons in high southern latitudes. I am convinced that the cause of the barometric depression round the South Pole is the centrifugal force of the west winds which revolve round the Pole, forming, in Maury's words, "an everlasting cyclone on a great scale," A similar cyclone is formed 